\title{
COMBINING WORK AND ELDERCARE: A NEGLECTED WORK-LIFE BALANCE ISSUE
}

\author{
Judith Davey \\ Sally Keeling \\ New Zealand Institute for Research on Ageing \\ Victoria University of Wellington
}

\begin{abstract}
Discussions about "work-life balance" and "family-friendly workplaces" mainly focus on working parents with young children. Employees who care for and support older relatives receive much less attention. But this issue will grow in importance as the population ages and labour shortages encourage middle-aged people to be fully involved in the workforce. As life expectancy increases many working people have parents in their eighties and nineties, often in need of care and support. How do they balance work and eldercare? A research project on working carers involved the employees of Wellington and Christchurch City Councils and found that about one in ten had eldercare responsibilities. Questionnaires and focus groups provided information on the type and extent of eldercare and how it is managed alongside work commitments. Such responsibilities can add to workers' stress and have an impact on productivity. Suggestions for employers arose from the study, including the need to develop policies on eldercare responsibilities among their staff as an emerging priority.
\end{abstract}

\section{Workforce and Population Change}

Several important trends underlie the emerging issue of work and eldercare.

New Zealand's population is ageing. In the coming halfcentury, its median age will rise from 36 to 46 and the percentage aged 65 plus will grow from 12 to 25 (Khawaja, 2000). The number of people aged 85 and over is expected to increase by 600 percent, to 290,000 . This age group is likely to require support and assistance, both formal and informal. Currently, only 15 percent of New Zealanders aged 85 and over live in the community independent of all service provision; 36 percent of people aged 75 and over have a moderate disability and 18 percent a severe disability (Ministry of Health 2002).

- Along with the population as a whole, the workforce is ageing, with a current median age of 40 (Davey and Cornwall 2003). This trend, along with declining birth rates, means that labour force growth will slow and by mid-century, based on present assumptions about participation, is expected to be negative (Stephenson and Scobie 2002). Thus New Zealand is predicted to face increasing labour and skill shortages (New Zealand Government 2001).

- Over the past 50 years there has been rapid growth in women's participation in paid employment. This is especially true for women in mid life, from age 40 onwards (Davey 2003a). Women are contributing to the workforce in greater numbers, whereas in the past they have traditionally been the major caregivers for people of all ages.

\section{Workers and Eldercare}

These trends produce a situation where workers in midlife are increasingly likely to have competing responsibilities towards their employers and to older people requiring care and support. Labour force participation rates for "older" workers (in the age range from roughly 45 upwards) are predicted to grow, as they respond to the combined incentives of labour shortages, improved health and longevity and the necessity to make greater provision for their own later lives. The OECD has highlighted the need for employment policies that accommodate older workers and help to overcome barriers that impede their participation (OECD 2000). International research forecasts that businesses that do not adequately prepare for an older workforce will face significant economic costs, which in turn will affect the growth of national economies (Robson 2001).

At the same time, older workers are the group most likely to have responsibilities for the care of elderly people, frequently their parents. As the population ages, the number of people with such responsibilities will increase, especially given the policy stance favouring "ageing in place". This implies that elderly people, often with significant disabilities or chronic health conditions, remain living in the community even if they need extensive care and support. Eldercare responsibilities may be a key factor in deciding whether older workers remain in the workforce and the extent of this involvement (full or part-time).

Hence, Positive Ageing, a central tenet of current government policy, which favours "productive lives in the economy and society" (Minister for Senior Citizens 2001), combined with the end of compulsory retirement 
(Human Rights Commission 1998), will generate concurrent pressure for men and women in midlife to stay in paid work longer. But at the same time "ageing in place" suggests that they will play increasing roles in support of their parents and family members (Ministry of Health 2002; Ministry of Social Development 2001; National Health Committee 1998).

\section{Previous Research}

Little is known in New Zealand about working carers of older adults, about strategies they use to balance work and caring and about procedures to assist them. There is, however, significant interest in the area, expressed by a range of organisations who attended meetings on MidLife Work Issues in 2002 and 2003 organised by the New Zealand Institute for Research on Ageing (NZiRA) and hosted by the Canterbury Development Corporation Ltd (Davey and Cornwall 2003; Davey 2003b; EEO Trust 2002).

Overseas, the literature on older workers, eldercare and the work-life balance is more extensive (Evandrou and Glaser 2001; Martin-Matthews 2001; Pickard 2001; SPRU 2001; TCRU 2001a and 2001b). Of particular significance is Juggling work and care: The experiences of working carers of older adults (Phillips, Bernard and Chittenden 2002). Phillips et al. point out that while the UK employers they studied are increasingly aware of the need for "family-friendly" policy and practice to support workers who care for young children, the question of eldercare responsibilities is not well recognised (SPRU 2000). Research has also found that employers perceive eldercare responsibilities as less demanding than childcare (Martin-Matthews 2001). However, caring for older people can involve protracted and unpredictable demands and caregiver burden has psychological, social and economic consequences (Noelker 2001). A USA report found that caregiving responsibilities affect workers' productivity, particularly because they need altered work schedules (Sheel and Coleman 2000). The personal and financial loss is high for individuals and employers: USA employers were estimated to have lost between US\$11.9 and US\$29 billion each year due to loss of productivity of full-time workers with caregiving responsibilities (Sheel and Coleman 2000).

Typical caregivers for older relatives are women in their mid forties (ENEPRI 2001; Martin-Matthews 2001; Robson 2001). Women who face disrupted work histories duc to child-rearing and then later curtail their involvement to undertake eldercare are often unable to save adequately for their retirement, leaving them dependent on state superannuation (Gee, $\mathrm{Ng}$ et al 2000; 2002). Innovative strategies to support eldercare need to involve employers and employees (Arksey 2001: Arksey and Hutton 2000). Phillips, Bernard and Chittenden (2002) found that very few designated family-friendly policies were taken up and used routinely by employees. Carers tended to use annual leave or time off in lieu. They were highly committed to their jobs, but experienced difficulty with inflexible schedules. The pressure of their jobs hindered their abilities to balance work and caring responsibilities. Other research found that the ability of working carers to maintain a positive and productive attitude is significantly enhanced when they have choice about their work arrangements and can organise their work around their caring commitments (Martin-Matthews 2001). The British Royal Commission on Long Term Care (1999) proposed special leave allowances for working carers with eldercare responsibilities. Other provisions that assist employees to blend work and caregiving responsibilities include flexible work conditions, special leave arrangements for emergencies and access to telephone links. Moreover, research has demonstrated the economic benefits to employers in implementing better work-life balance policies in the area of eldercare. These include improved employee retention, higher productivity, reduced absenteeism and lower stress (SPRU, 2000).

\section{Research Design}

The approach used by Phillips, Bernard and Chittenden (2002) was adapted, with permission, to New Zealand conditions. Two local authorities, the Wellington City Council (WCC) and Christchurch City Council (CCC), agreed to provide the sites for this study. Both have mixed workforces in terms of occupational categories and a good balance by age and gender. The New Zealand research design incorporated three steps:

- All employees received a screening questionnaire, asking whether they provided informal care to an older person or persons, defined as "looking after or giving care to anyone (one or more persons) over the age of 65 - family members, friends, neighbours or others - because they have long-term physical or mental disability or problems related to old age".

- A self-administered questionnaire was distributed to working carers who were willing to participate. This collected information on caregiving patterns and working life in relation to eldercare.

- Group interviews with working carers in the two cities.

\section{Key findings}

Responses to the screening questionnaire suggest that at least 7.8 percent of the CCC workforce and 10.8 percent of the WCC workforce have eldercare responsibilities overall 9.2 percent. This is similar to the results from the British survey (Phillips, Bernard and Chittenden 2002). Of the 254 employees with eldercare responsibilities willing to participate in the questionnaire survey, 134 returned usable forms. Four group interview sessions were competed in each centre, involving 32 respondents in all (Davey and Keeling 2004).

The respondents are predominantly Pakeha, well educated, and in professional, technical and clerical roles. They are mainly female ( 72 percent), employed full-time (80 percent), and are long-term employees with the councils (average 9 years).

The care recipients are also mainly female ( 71 percent) with an average age of 81 . Mothers and fathers of the 
carers together accounted for 62 percent of the care recipients and including mothers-in-law and fathers-inlaw the total was 75 percent. This study did not include significant representation of spouse carers, although this is a very common situation among older people. The majority of care recipients ( 72 percent) live in their own homes, with 17 percent in residential care and 11 percent in the same household as the working carer. It is clear that the need for care does not cease when the older person enters residential care.

\section{Patterns of Care-giving}

This paper concentrates on the workforce implications of eldercare, but patterns of care-giving are summarised briefly here.

The most common type of care provided by the respondents is social and emotional support (provided by 92 percent), which involves activities such as checking on the older person by phone, visiting and taking them out. This is followed by household assistance ( 87 percent), such as help with shopping, laundry, preparing meals, gardening and household maintenance. Administrative support (72 percent) comes third in importance, and includes assistance with completing forms and documentation, managing money and arranging assistance from agencies. Personal care is the least common form reported (47 percent) and may involve help with dressing, washing, eating and taking medication. A variety of other types of support were cited, from being on call, managing hospital visits, providing transport and liaison with other family members and health professionals.

Women respondents are more likely than their male counterparts to provide all types of care, especially social and emotional support, and personal care. A higher proportion of women provide care on a frequent basis. Few of the working carers taking part in this study provide very long periods of care: 84 percent give less than 10 hours per week. However, on top of full-time work and personal or domestic commitments, this is still significant. Three quarters of the working carers, both men and women, have help from other family members and/or from health professionals and community services, but 41 percent of the women say that they have the main responsibility, as against 30 percent of the men. Sharing of care, especially between siblings - usually the adult children of the care recipients - is a topic which can give rise to considerable tension and resentment, as was clear from the group discussions. Participants also observed that decisions made by formal carers (doctors, hospitals) may increase stress on informal carers, through inconvenient scheduling of appointments, cancellation of appointments, early discharge from hospital, or lack of communication with services such as meals on wheels or home care. There was discussion around the quality of health services, especially noting situations where coordination had been inadequate and carers had been left filling in the gaps.

\section{Balancing Work and Care}

Working carers report that their employers and colleagues in the two city councils are generally supportive of their situation, although most are conscious that their workloads build up if they are away unexpectedly. Colleagues and managers generally know about their caregiving situations, and acknowledge that eldercare may be less predictable than childcare. Respondents commented:

To be a working parent is something you plan, and you know you have to take certain things into account, but to be a working carer is not something you planned.

Often you will get up there to pay Mum a visit and she is upset or depressed about something. Dealing with the depression is quite difficult. You cheer them up and think - I've got to go back to work in 10 minutes. You have a limited timeframe.

However, some people mentioned a lack of understanding on the part of younger colleagues and managers, and that eldercare could at times be a conversation-stopper in the tearoom. Workplaces where there is a predominance of younger staff may be more understanding of issues with children and partners, than with elders.

As shown in Table 1, the most frequently-used method of coping with eldercare responsibilities during work hours, beyond making the occasional phone call, is to use annual leave, which 48 percent of the working carers did at least once in the six months before the survey. Some people are concerned about using up available leave when they might need it for a crisis later. Others say that being unable to arrange alternative care means that they have not had a "proper" holiday for some time, which impacts on their own energy and, ultimately, their health and productivity. Time in lieu, flexitime, and sick or domestic leave are each mentioned by 30 percent of the working carers as coping strategies they have used. Very few respondents took leave without pay. Almost half had asked other family members to provide care but very few had arranged paid care.

Participants in the discussion groups often mentioned the benefits of being able to use the telephone at work, to make arrangements and appointments and to check up on their family member. However, phone communication can also be a source of anxiety - "Sometimes Mum leaves the phone off the hook, so I spend the whole day worrying." Some ambivalence is also expressed about telephone use, around privacy and guilt relating to costs and time spent, and about disturbing others' working environments. One participant was very embarrassed, having to shout over the phone to her deaf father.

There are clear differences between the methods adopted by men and women working carers. Women are more likely to use annual leave, sick leave and leave without pay than men, but men are more likely to take leave in lieu or use flexitime. Women are also more likely than men to arrange for other family members to provide the 
Table 1: Methods of coping with eldercare, frequency of use (percent of working carers)

\begin{tabular}{|c|c|c|c|c|}
\hline & Never & Once & $\begin{array}{l}\text { More } \\
\text { Once }\end{array}$ & $\begin{array}{l}\text { than } \\
\text { Total }\end{array}$ \\
\hline \multicolumn{5}{|l|}{ Leave from work } \\
\hline Taken leave without pay & 91 & 2 & 7 & 100 \\
\hline Taken domestic leave & 78 & 10 & 12 & 100 \\
\hline Taken sick leave & 73 & 15 & 12 & 100 \\
\hline $\begin{array}{l}\text { Taken time in lieu, or worked flexitime in consultation wit } \\
\text { supervisor/colleagues }\end{array}$ & 69 & 11 & 20 & 100 \\
\hline Taken annual leave & 52 & 20 & 28 & 100 \\
\hline \multicolumn{5}{|l|}{ Other methods } \\
\hline Paid someone else to provide care & 94 & 1 & 5 & 100 \\
\hline Arranged with another family member to provide the care & 52 & 12 & 36 & 100 \\
\hline Made phone calls or provided care yourself in work time & 37 & 9 & 54 & 100 \\
\hline
\end{tabular}

care which they themselves would usually give. However there is no difference in the proportion who take domestic leave and a high proportion of both men and women carers have provided care (or made phone calls) in working time.

Arranging time off for health and professional appointments is mentioned as a problem, but also as a tangible benefit of workplace flexibility. Some people use annual leave for these appointments:

I use my annual leave if I need to take Mum to the specialist because it is always during working hours, and my hrother has to take annual leave from his job too. We have turns at doing that.

It would he really good if you could specify appointment times so you could get there at the beginning or the end of rour working day.

Sixty three percent of the working carers report that they had to deal with an eldercare crisis in the previous six months and half of these people have experienced more than one crisis. More than a third report having had time off work to deal with crises. The older the care recipient, the more likely the working carer is to have taken time off from work. Women working carers take time off in a crisis more frequently than their male counterparts, and are more likely to have had more than a week off in the previous six months.

The questionnaire presented respondents with a range of strategies that could help in managing eldercare and paid work, asking if they had considered or used them in the previous six months. Strategies related to paid work, such as reducing work commitments or finding a job closer to the care recipient, were not highly ranked (Table 2 ). Making sure the older person's affairs were in order and discussing care arrangements with other family members were the options most often cited. The overall rankings of strategies were fairly similar between men and women, except that women were more likely to have put money aside and men were more likely to have looked for long term care options.

A very strong theme in the group discussions was access to relevant and accurate information on eldercare services and how to manage work and care. The participants feel a clear need for a consolidated source of information, and discussed whether this should be internet or telephone based.

In terms of care of the elderly and all the types of services available, I haven't found a website where it is all on. It seems they are a bit behind putting it all on one site, or I haven't found it.

It would be really nice to pick up the phone and say - I don't know what to do. I am stuck with this problem, where do I go from here?

Some health professionals were described as "not forthcoming" and this further adds to stress on carers. "It is terribly hard to find out about government services and support - and I work in a public library!"

Not having time to access information is an issue for me. It would be useful if the GP/hospital had an information pack for carers on where they can get assistance and what facilities are available, so one didn't have to go hunting for this information. One can't sit on the phone for hours tracking down services. 


\begin{tabular}{|llll|}
\hline & $\begin{array}{l}\text { Male } \\
\text { percent }\end{array}$ & $\begin{array}{c}\text { Female } \\
\text { percent }\end{array}$ & $\begin{array}{l}\text { Total } \\
\text { percent }\end{array}$ \\
\hline Discussed care arrangements with other family members & 53 & 72 & 66 \\
Made sure that older person's affairs were in order & 69 & 65 & 65 \\
Sought information about community services for seniors & 42 & 45 & 43 \\
Modifying older person's home to make care provision easier & 25 & 30 & 28 \\
Looked into places that provide long term care & 28 & 20 & 22 \\
Put money aside to help meet older person's needs & 11 & 21 & 18 \\
Finding ways for you and the person(s) you care for to live closer to & 11 & 20 & 17 \\
each other & & & 13 \\
$\begin{array}{l}\text { Considered reducing your work commitments to meet increasing care } \\
\text { and support needs. }\end{array}$ & 8 & 16 & 10 \\
Looked for a job that was closer to where they live & 11 & 10 & \\
\hline
\end{tabular}

\section{Discussion and Conclusions}

The picture of life as a working carer emerging from this New Zealand study is generally consistent with comparable studies from the UK, Australia and Canada. The results illustrate caregiving situations which are part of the work/life context for about one tenth of the workforce in the two councils. While these situations are not generally intensive, they are often long term, include both potential and actual crisis care and clearly entail strain and stress. The study shows how the links between caregiving situations and workplace contexts are twoway. At times caregiving impacts on work, and at other times work impacts on caregiving capacity. In their UK study, Phillips et al (2002) make a distinction between "balancing" and "juggling". While managers and carers may appreciate one another's viewpoints, managers have a primary interest in balancing the needs of the organisation against the needs of employees. Carers express their issues more in terms of juggling multiple demands - to their employers, partners and children, the care recipients, their communities and to themselves. The people who participated in the New Zealand study use both terms to describe their dual roles as carers and workers. They refer to balancing responsibility to their employer with responsibility to their families and refer to concerns about fairness, equity and reciprocity in these relationships. They clearly refer to their personal juggling of multiple roles. They wonder how they fit all their activities into and around their working lives and appreciate where the social fabric of their lives might be wearing thin.

The employment environment in the two councils is described as flexible and supportive, despite the absence of explicit policies or procedures aimed at the situation of working carers. This raises questions about whether a rising demand for informal care and the implications of an ageing workforce will combine to generate clearer policy developments, or, conversely, feed ageism. This research identifies risks and opportunities for both workforce and community.

\section{What might help?}

Workforce development could be enhanced by more open discussion of the interface between paid employment and informal eldercare. Employers might consider developing opportunities and resources for working carers to share experiences and to explore information on service availability, perhaps through work-based support groups. Making leave provisions more explicit and relevant to workers who provide eldercare would be welcomed. Formal options for the management of eldercare in relation to employment have been explored and adopted in other countries and settings. These include arrangements such as "annual hours of work" packages, "caregiving sabbaticals" or employer/worker shared support for day care and information services. It will also be important to ensure that such moves are extended equitably to workers at all levels in an organisation, and in all occupations and workplace settings. While there is clear employer goodwill in the examples examined, there may be questions about fairness within and across complex organisations, and about how to meet the needs of workers where flexibility is structurally difficult.

However, many of the most commonly reported strategies for eldercare management are community and family based, rather than related to working conditions. Most working carers in this study agree on the need for service coordination and open dialogue about what family carers can and cannot offer. Even within the same city, people found a lack of consistency in information they had gleaned from different parts of the health system. Relationships with the older person's general practitioner 
were a topic of discussion, recognising that GPs can be either a weak or a strong link in creating and managing a supportive environment for dependent elderly people and their informal carers.

Making relevant and accurate information widely and publicly available would also help to improve understanding of the growing need for eldercare, and the situation of working carers. The study indicated the need for improved understanding among work colleagues, work supervisors and managers, in the general community and on the part of older people themselves, who may find it difficult to express their wishes clearly. If the older person delays asking for help or has refused help and services offered, this can make things harder for the carers. They also caution other working carers not to ignore their own needs when negotiating with family members, both older people and those in their own and following generations - "don't be a hero" said one person. Having access to reliable and appropriate information about services would also assist in family discussions, where the dynamics are not always straightforward between siblings, between parents and adult children, between marital partners and in the context of "in-law" or "de facto" relationships.

The working carers in this study make limited mention of the financial costs of care, possibly because many are in occupations likely to have average or above salaries. But other, less tangible, costs of care are noted, which are difficult to measure or are "beyond a dollar value" (Belgrave and Brown 1997). The discussions touched on the costs of holidays not taken, time not available for personal relaxation or for spending with friends and younger family members, personal health costs and loss of goodwill in family relations. Of particular concern is the correlation between the highest levels of care and the most negative attitudes.

Research of this type needs to be extended in order to lay a firmer foundation of evidence on the relationship between paid employment and informal eldercare in New Zealand. Further research should cover a wider variety of workplaces and workforces, including employers in central government agencies, manufacturing, primary industry and service delivery. This would allow deeper investigation of variations between communities, occupations and sectors, as well as differences based on gender and ethnicity. More systematic interviewing of employers and managers, and their representative groups would also be fruitful, as well as research involving unions and workers' groups.

This research was designed to explore the perspectives and experiences of people in their dual roles as workers and carers. It did not seek the perspectives of care recipients or family members with whom the research participants may share care. A multi-dimensional approach, using "triangulation", would bring together these different perspectives and produce a much richer and deeper view of informal care. A variety of methodologies would also be needed to pick up those who chose not to participate in this study (or similar studies), or those who may already have left the workforce for reasons relevant to informal eldercare responsibilities or lack of workforce flexibility.

Reactions to the experience of providing care to older people while still engaged in the paid workforce, which have been recorded and analysed in this report, reflect a complex and personal balancing act. The working carers talk about emotional attachment to the older people they care for; acceptance of, and sometimes resignation to, the responsibility of care. They acknowledge that their own needs might sometimes be compromised, in terms of a curtailed social or recreational life. They acknowledge also that they are supported to a greater or lesser extent by their employers, other family members and sometimes by friends. They seek to have effective links with health and social service agencies in order to provide bettercoordinated care for their elders, but they also are aware of gaps and breaks in these networks. The response of the working carers who took part in this study suggests that in some way this project may have helped to reduce their sense of isolation. Recognition from within the workplace that they are not alone in their situation, and that there may be some prospect of effective support for working carers, is an important part of building public understanding of ageing in New Zealand today. While at any one time maybe only one in ten employees is defined as a working carer of older people, over a working lifetime it is highly likely that most workers will experience some dimensions of this dual role.

\section{References}

Arksey H. (2001). Employers' Provisions for informal carers. Working paper contributed to Working Carers of Older Adults: Current Issues and Future Research Agendas, Pre-Conference Workshop, August 31, 2001. Stirling: British Society of Gerontology.

Arksey H. and Hutton S. (2000). "Community care for adults team" http://www.york.ac.uk/inst/spru/ research/summs/employ_prov.htm 10/7/02).

Belgrave, M. and Brown, L. (1997). Beyond a dollar value: informal care and the Northern Region Case Management Study. Auckland: North Health, Waitemata Health and Massey University.

Davey J. (2002). Active Ageing and education in mid and later life. Ageing and Society, 23, 95-113.

Davey, J. (2003a). Two Decades of Change in New Zealand: From Birth to Death V. Wellington: Institute of Policy Studies.

Davey, J. (2003b). Human Capital Issues In An Ageing Workforce. Social Policy Journal of New Zealand, 20, 156-172.

Davey, J. and Cornwall, J. (2003). Maximising the Potential of Older Workers. Wellington: New Zealand Institute for Research on Ageing. 
EEO Trust (2002). EEO Trust: Summary of work on age. Paper prepared for NZiRA Meeting on Research on Work and Education in Mid-Life, 26/7/02. Christchurch.http://www.eeotrust.org.nz/ worklife/business.shtml (accessed 26/07/02).

ENEPRI (2001). Newsletter of the European Network of Economic Policy Insititutes. http://www.cepii.fr. (Accessed 19/05/03)

Evandrou M. and Glaser K. (2001). Family Care and Paid Work: Multiple Role Occupancy in Britain presented to Working Carers of Older Adults: Current Issues and Future Research Agendas, PreConference Workshop, August 3, 2001. Stirling: British Society of Gerontology.

Gee, S., Ng, S., Weatherall, A., Liu, J., Loong, C. et al. (2002). Saving ourselves: gender issues in making provision for ones own retirement. Australasian Journal of Ageing 21(1): 30-35.

Gee S., Ng S., Weatherall A., Liu J., Loong C. et al. (2000). Life after 40: work and retirement plans. Wellington: Victoria University of Wellington.

Khawaja, M. (2000). Population Ageing in New Zealand. Paper given at a seminar on the demographics of population ageing in New Zealand, held in Wellington on 26 July 2000 and in Auckland on 27 July 2000.

http://www.stats.govt.nz/domino/external/web/abo utsnz.nsf/htmldocs/Ageing+Population (Accessed 23/01/2002).

Martin-Matthews, A. (2001). Working Carers of Older Adults: Insights from CARNET: The Canadian Aging Research Network" presented to Working Carers of Older Adults: Current Issues and Future Research Agendas. Pre-Conference Workshop, August 31, 2001. Stirling: British Society of Gerontology.

Ministry of Health (2002). Health of Older People Strategy: Health Sector Action to 2010 to Support Positive Ageing. Wellington: Ministry of Health.

Minister for Senior Citizens (2001.) The New Zealand Positive Ageing Strategy, Wellington: Senior Citizen's Unit, Ministry of Social Policy.

Ministry of Social Development (2001). Positive Ageing in New Zealand: Diversity, participation and change, Status Report 2001. Wellington: Ministry of Social Development.

National Health Committee (1998). How should we care for the carers? Wellington: National Health Committee.

New Zealand Government (2001). Workforce 2010: A document to inform public debate on the future of the labour market in New Zealand. Wellington: New Zealand Government.
Noelker, L. (2001). The backbone of the long-term-care workforce. Generations 25(1): 85-91.

OECD (2000). Reforms for an ageing society. Paris: Organisation for Economic Co-operation and Development.

Phillips, J., Bernard, M. and Chittenden, M. (2002). Juggling Work and Care: The Experiences of Working Carers of Older Adults. York: Joseph Rowntree Foundation.

Pickard L. (2001). Synopsis of work on informal care PSSRU, LSE, presented to Working Carers of Older Adults: Current Issues and Future Research Agendas, Pre-Conference Workshop, August 31, 2001. Stirling: British Society of Gerontology.

Robson, W. (2001). Aging Populations and the Workforce: Challenges for Employers. Winnipeg: British-North American Committee.

Royal Commission on Long Term Care (1999). With Respect to Old Age. Long Term Care: Rights and Responsibilities. London: The Stationary Office.

Sheel, P. and Coleman B. (2000). Caregiving and Longterm Care. Washington: Public Policy Institute, AARP.

SPRU (2000). mployers Provisions for informal Carers. York: Social Policy Research Unit, The University of York.

SPRU (2001). Informal care over time Research Works, Social Policy Research Unit, The University of York.

http://www.york.ac.uk/inst/spru/pubs/rworks/aug2 001.pdf (Accessed 10/7/02).

Stephenson, J. and Scobie G. (2002). The Economics of Population Ageing. Wellington: New Zealand Treasury.

TCRU (2001a). Fifty Plus: Caring and work after 50. Progress report from Thomas Coram Research Unit. London: University of London.

TCRU (200lb). Four care workforce research projects. Presented to Working Carers of Older Adults: Current Issues and Future Research Agendas, PreConference Workshop, August 31, 2001. Stirling: British Society of Gerontology. 